\title{
Effects of a Virtual Physical Activity Program within the Context of Social Distancing During the Covid-19 Pandemic
}

\author{
a Physical Education Unit, Western Campus, University of Costa Rica, Costa Rica \\ b School of Physical Education and Sports, University of Costa Rica, Costa Rica \\ c Human Movement Sciences Research Center, University of Costa Rica, Costa Rica \\ *Corresponding author Email: mynor.rodriguez@ucr.ac.cr \\ DOI: https://doi.org/10.34256/ijpefs2115
}

Keven Santamaría-Guzman ${ }^{\mathrm{a}, \mathrm{b}}$ (D), Mynor Rodriguez-Hernandez a, ${ }^{\text {(D) }}$ \& Jose Moncada-Jimenez ${ }^{\mathrm{b}, \mathrm{c}}$ (iD)

Received: 17-02-2021, Revised: 22-03-2021; Accepted: 24-03-2021; Published: 26-03-2021

Abstract: To determine the effects of a virtual physical activity (PA) program in college students during social distancing due to COVID-19. 44 college students, male and female. Methods: Participants completed self-reported measures of the International Physical Activity Questionnaire, weekly PA, and a short-survey of the educational experience during social distancing. Participants completed the instruments at baseline and after 10-weeks of an on-line virtual PA program. Increased overall PA $(p=0.040)$ and transportation PA $(p=0.004)$, leisure-time PA ( $=0.031)$ domains increased following the program. The sitting time increased following the intervention $(p=$ 0.0001). Students who failed to comply with at least $150 \mathrm{~min} /$ week of PA reduced the frequency of positive emotions compared to those who complied $(p=0.017)$. Social distancing and daily college tasks seem to lessen the effect of PA on sedentary behavior in college students regardless of an increase in PA.

Keywords: Physical activity, Social distancing, Virtuality, College students

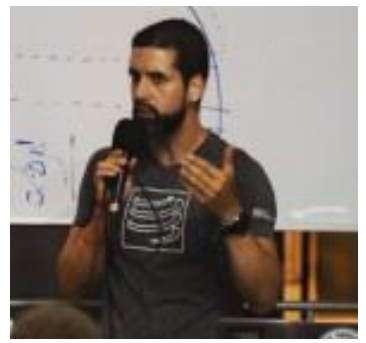

kinematics, footwear impact on performance and athlete's injury prevention, athlete's performance. He is a member of the American College of Sports Medicine and the American Network for Research in Human Movement Sciences. He also collaborates with the Holistic Program for Older People at the University of Costa Rica and the International Triathlon Union.

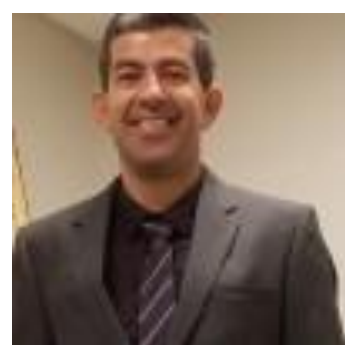

Dr. Mynor RodriguezHernandez lives in San Ramon, Costa Rica. He is a Full Professor at the University of Costa Rica, Western Campus. His research focuses on projects that would impact community needs regarding physical activity, health, and quality of life. All contributions of physical activity behavior, sedentary behavior, sitting time, breaking sedentary time to health and quality of life. And possible ways to increase exercise adherence in adult populations. He is a member of the American College of Sports Medicine, the International Society for Physical Activity and Health, and the American Network for Research in Human Movement Sciences. He has participated as a presenter in international conferences. Dr. Rodriguez-Hernandez collaborates as a reviewer of reputed journals related to the field of human movement sciences.

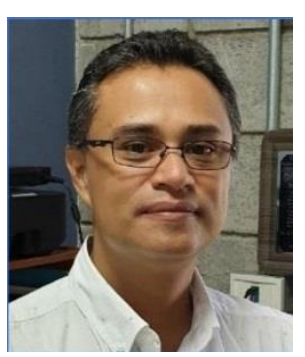

Dr. José Moncada-Jiménez holds a Ph.D. in Biomedical Sciences from the University of Costa Rica, a post-doctoral internship at Baylor University in Texas, USA, and postgraduate studies at The Ohio State University, in Ohio, USA. He also holds an M.Sc. in Movement Sciences with a specialization in Exercise Physiology from Springfield College, in Massachusetts, USA. He is the founder of the Human Movement Sciences Research Center (CIMOHU) of the Vice-rectory for Research of the University of Costa Rica. He has taught courses in research methods, statistical analysis, exercise physiology, and measurement and evaluation. 
He is currently a full-time professor and researcher at the University of Costa Rica.

\section{Introduction}

Sedentary behavior is a risk factor for developing a myriad of negative health outcomes, including cardiovascular disease, cancer, diabetes, an increased mortality [1]. Physical activity (PA) guidelines have been developed and encouraged worldwide to reduce the deleterious effects of sedentary behavior [2 -4]. These guidelines are supported by an abundant body of evidence showing the short- and long-term positive effects of different modes of PA, including exercise training.

Exercise has been called a polypill given its potential for preventing or treating chronic diseases [5]. Several health benefits have been summarized before in systematic reviews and meta-analyses [6-9], including enhanced mood, cognitive and brain function from childhood to senescence, and an attenuated risk for cognitive impairment and dementia during ageing [10]. Other metabolic and physiological benefits include reductions in systolic and diastolic blood pressure, endothelial function, cardiorespiratory function, glucose regulation, fat oxidation [11-17].

Exercise training strategies have shown positive changes in body composition in spite of unobserved reductions in sedentary behavior [18]. Thus, engaging and maintaining a physically-active behavior (i.e., adherence) has been a challenge for sedentary people. Recent evidence on athletes [19], suggest that past behavior exert a residual effect on the future intention to exercise (i.e., adherence), and that supportive environments increase levels of autonomous motivation and higher rates of future exercise behavior. On sedentary subjects the motivations predicting exercise adherence are different; for example, a perceived enjoyment, a sense meeting a challenge, positive health, and better or enhanced strength and endurance [20].

During the late 2019 and early 2020, a form of the severe acute respiratory syndrome coronavirus 2 (SARS-CoV-2) caused the coronavirus disease (COVID19) that spread worldwide causing thousands of deaths. Extensive hand sanitation, social distancing and isolation were recommended by international and national health organizations to reduce the virus contagious and mortality among the population [21]; thus, majority people stay at home working and studying remotely.
Costa Rica implemented measures to fight the pandemic (e.g., closing education institutions, public and private transportation restrictions), and as of July 2020 the mortality rate ranked among the lowest in America [22]. Virtual tools, on-line platforms (e.g., Skype $^{\circledR}$, Zoom $^{\circledR}$, MS Teams $^{\circledR}$ ) and social media Apps (e.g., Facebook ${ }^{\circledR}$, WhatsApp ${ }^{\circledR}$, Instagram ${ }^{\circledR}$ ), were suggested to educators to assist in lecturing their students and maintain constant communication. Noone in the world was prepared for the pandemic, and these measures provoked the population, including students and faculty, to increase their sedentary time by seating for several hours in front of a computer, telephone, tablet or television screen $[23,24]$.

The effects of the increased sedentary behavior during COVID-19 are unknown [25]; however, the negative health impact may include increases in biomarkers related to metabolic syndrome (i.e., insulin resistance, obesity, inflammatory cytokines), as well as changes in dietary habits [26, 27]. Yet, exercise science specialists still recommend to remain active during the pandemic while keeping all necessary protection measures $[28,29]$. Therefore, the purpose of this study was to determine college students' PA behavior and experiences obtained during a 10-week virtual PA program.

\section{Methods}

\subsection{Participants}

All procedures followed the standards set forth by the latest revision of the Declaration of Helsinki. A non-probabilistic sample of forty-four college students who signed for a required PA class, consented to participate in a 10-week virtual PA program. The inclusion and exclusion criteria to participate in this study indicate that students had to be healthy as determined by the PAR-Q instrument, enrolled in a sport class, willing to complete all online self-reported questionnaires, and the virtual 10-week PA program.

\subsection{Measures}

Anthropometrics. For descriptive purposes, participants were asked to self-report their estimated body weight $(\mathrm{kg})$ and height $(\mathrm{cm})$. Then, body mass index $\left(\mathrm{kg} / \mathrm{m}^{2}\right)$ was computed. This procedure has been used before in large-scale health surveys [30].

Physical Activity Assessment. The PA was assessed using the Spanish long version of the International Physical Activity Questionnaire (IPAQ) (www.ipaq.ki.se.). The IPAQ is a global standardized 
instrument used to record physical activity levels in 1869 years old adult population. Psychometric properties include a validity of 0.67 and reliability 0.80 [31]. This IPAQ version is comprised of 27 items providing information on time spent walking, vigorous and moderate intensity PA and in sedentary activity during the previous seven days. The instrument measures of level of PA through questions in four domains: work, home, transportation, and leisure time. The sitting time questions, is an additional indicator and is not included as part of any summary score of PA as indicated by the scoring protocol of IPAQ. This is used as the indicator to reflect time spent in sitting rather than METminutes, which would suggest an estimate of energy expenditure. In addition to the original IPAQ, a few questions were added in order to record how much time participants spent doing college homework, watching TV and playing video games.

The PA indicator is expressed continuously in units of metabolic equivalent of task (MET) as MET$\mathrm{min} /$ week, and categorically following these criteria (Table 1).

The MET is defined as an objective measure of the ratio of the rate at which a person expends energy, relative to the mass of that person, while performing some specific PA compared to a reference set by convention at $3.5 \mathrm{ml} \mathrm{O}_{2} \cdot \mathrm{kg}$ body $\operatorname{mass}^{-1} \cdot \mathrm{min}^{-1}$ (i.e., energy expended when sitting quietly) [32].
METs are a way to calculate energy requirements and exercise intensities [33], and the unit used, MET-minute, is calculated by multiplying the MET corresponding to the type of activity by the minutes of its execution in a day or in one week, this is how it is expressed in MET-minute/week for each domain. These were calculated as follows: walking activities= (3.3 $\mathrm{x}$ walking minutes $\mathrm{x}$ walking days); moderate activity $=(4.0 \times$ moderate activity minutes $x$ moderate activity days $)$; vigorous activity $=(8.0 \times$ vigorous activity minutes $x$ vigorous activity days) [32].

Report of weekly PA. This instrument allowed participants to register all physical activities performed within the week. The instrument comprised seven items to evaluate the number of sessions performed, time invested and intensity of each session. Also, participants reported the time spent sitting, time spent watching $\mathrm{TV}$, and time spent playing video games.

Educational experience in virtuality: This instrument comprised four items to evaluate the perceived feelings related to the university requirements for students and the limitations that prevented the adequate accomplishment of the exercise program.

\subsection{Procedures}

By design and due to the social distancing situation caused by the COVID-19, college students enrolled in sport courses, consented to participate in a virtual PA program. At baseline, participants completed the IPAQ and immediately were given the corresponding PA program to be completed.

Table 1 Criteria for evaluating the level of physical activity categorically

\begin{tabular}{ll}
\hline Physical Activity Level & \multicolumn{1}{c}{ Description } \\
\hline High & Vigorous-intensity activity on at least 3 days and accumulating \\
& at least $1500 \mathrm{MET}$-min/week \\
Moderate & A combination of walking, moderate-intensity or vigorous \\
& intensity activities achieving a minimum of at least 600 MET- \\
& min/week. \\
Low & Those individuals who not meet criteria for categories 2 or 3 \\
& are considered low/inactive.
\end{tabular}


Participants were asked to accomplish at least 150 min of PA during each week. The PA program consisted in one supervised session per week, via Zoom $^{\circledR}$ platform; the other sessions had to be performed by themselves without supervision. Participants had access to a YouTube channel previously set up with short videos showing over a hundred exercises from which the specific workouts, included in the program, were chosen. The PA program was designed to allow participants to achieve the PA recommendations during COVID-19 set up by de American College of Sports and Medicine [34]. Every week, participants completed a PA report to track the program accomplishment. After 10 weeks, participants completed again the IPAQ and a final report instrument designed to collect data from the feeling experiences obtained during and after the virtual process.

\subsection{Statistical analysis}

All analyses were performed with SPSS 26.0 (IBM SPSS, Armonk, NY). Descriptive statistics are presented as the mean \pm SD. Paired-samples t-student tests compared mean MET-minutes/week between baseline and week-10 PA. Sitting time reliability was studied by Pearson correlation between IPAQ scores and the mean weekly PA report. The participant's emotions before and after the PA intervention were categorized into negative and positive feelings; then, chi-squared tests for each set of emotions studied the association between those participants who achieved at least 150 min of PA per week and those who did not meet the goal. Statistical significance was set a priori at $p<0.05$.

\section{Results}

Participants were 34 males and 10 females. The physical characteristics of the participants are summarized in table 2 .

Paired-samples t-student tests were used to compare mean MET-minutes/week between baseline and week-10 PA (Table 3). The sitting time increased in $\sim 2 \mathrm{~h}$ from baseline to the end of the intervention (229.55 \pm 76.55 vs. $342.84 \pm 36.87$ min; $p=0.0001)$.

The weekly report of PA indicated that there were no changes in the volume of PA $(p=0.987)$ performed and the time spent in sedentary activities $(p$ $=0.398$ ) during the 10 weeks of the intervention (Figure 1). The self-reported sitting times were consistent as registered in the IPAQ and the weekly report $(r=0.47 ; p=0.001)$.

The negative (i.e., exhaustion, low motivation, disappointment, I haven't learned anything, perception of low educational quality, low academic performance, dispersion, irritability, anxiety, indecision, detachment, and insomnia) and positive (i.e., interested, deluded, better performance, I have discovered my self-taught skills, high motivation, better academic performance, tranquility, determination, concentration, relaxation, patience, and vigor) feelings and symptoms were grouped for analysis.

A chi-square test of independence was performed to examine the relation between students lacking to perform at least $150 \mathrm{~min} /$ week and those performing $\geq 150 \mathrm{~min} /$ week of PA before and after the intervention on the frequency of negative emotions.

Table 2. Physical characteristics of the participants $(n=44)$. Values are $M \pm S D$

\begin{tabular}{lccc}
\hline \multicolumn{1}{c}{ Variables } & Females $(\mathbf{n}=\mathbf{1 0})$ & Males $(\mathbf{n}=\mathbf{3 4})$ & Cohort $(\mathbf{n}=\mathbf{4 4})$ \\
\hline Age (yr.) & $18.81 \pm 0.67$ & $19.61 \pm 1.75$ & $19.43 \pm 1.60$ \\
Weight $(\mathrm{kg})$ & $55.30 \pm 5.21$ & $70.76 \pm 11.97$ & $67.25 \pm 12.59$ \\
Height $(\mathrm{cm})$ & $159.80 \pm 6.00$ & $174.44 \pm 5.99$ & $171.11 \pm 8.58$ \\
Body Mass Index $\left(\mathrm{kg} / \mathrm{m}^{2}\right)$ & $21.67 \pm 1.91$ & $23.21 \pm 3.48$ & $22.86 \pm 3.24$ \\
\hline
\end{tabular}


Table 3 Comparison of total and domain physical activity between baseline (week 0 ) and week 10 of the intervention. Values are $M \pm$ SD MET-min/week

\begin{tabular}{lccc}
\hline Physical Activity Domain & Baseline & Week 10 & p $=$ \\
\hline Work & $225.27 \pm 517.39$ & $451.33 \pm 599.88$ & 0.119 \\
Transportation & $275.66 \pm 386.31$ & $672.27 \pm 880.08$ & 0.004 \\
Domestic and garden & $596.70 \pm 782.36$ & $441.52 \pm 405.87$ & 0.291 \\
& & & \\
Leisure-time & $662.68 \pm 742.21$ & $1041.61 \pm 1322.58$ & 0.031 \\
& & & 0.040 \\
All Physical Activity & $440.83 \pm 334.25$ & $651.68 \pm 635.04$ & \\
\hline
\end{tabular}

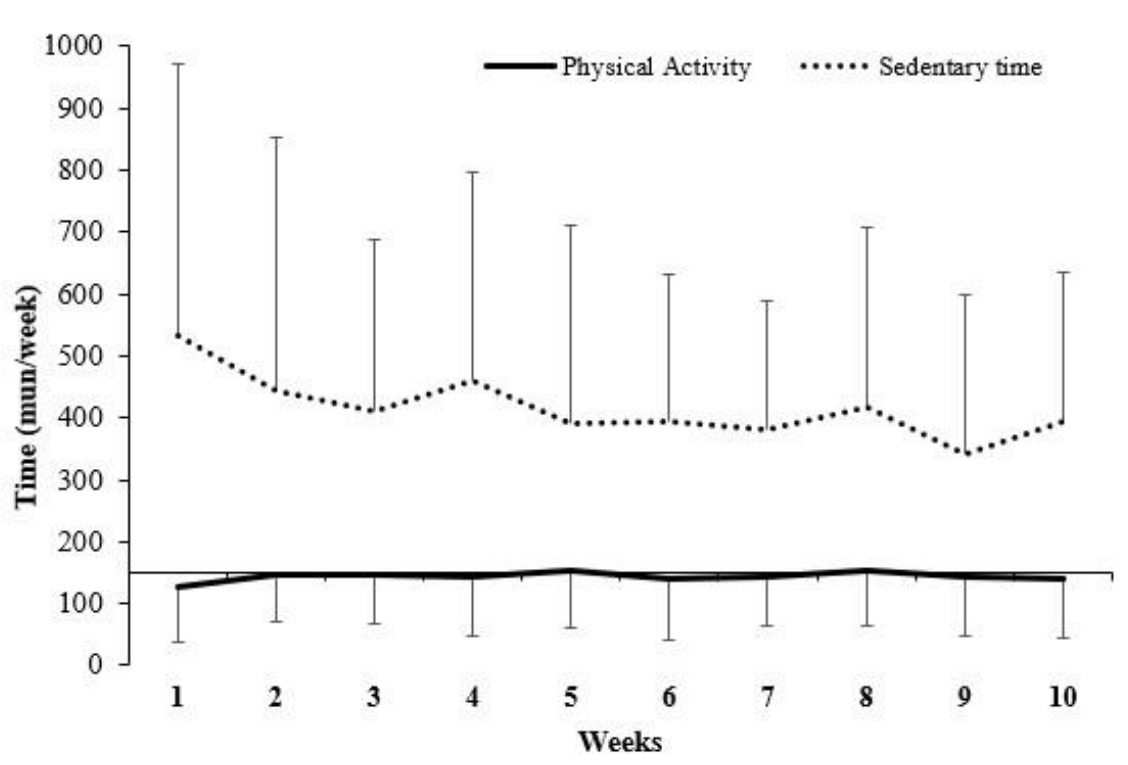

Figure 1. Minutes per week spent in sedentary and physical activities.

Values are mean \pm SD. The line crossing the "Y" axis shows the recommended physical activity time of $150 \mathrm{~min} /$ week

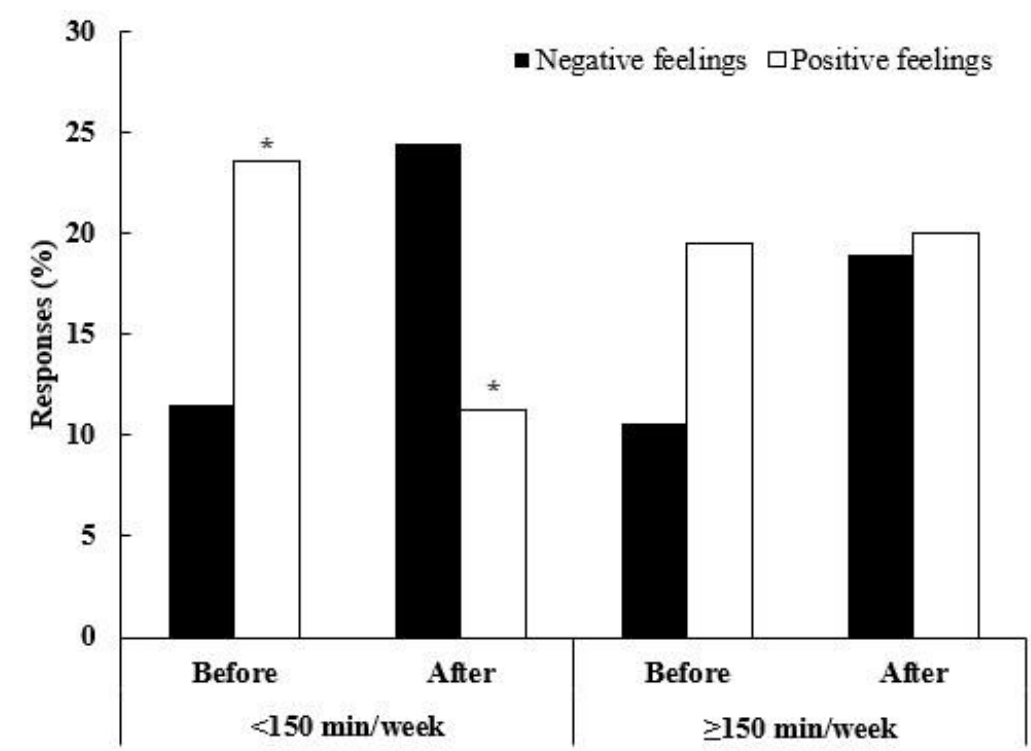

Figure 2. Responses of students unable to meet $150 \mathrm{~min} /$ week of PA and those meeting the weekly PA recommendation. Different letters are statistically different $(p=0.017)$. 
Table 4 Barriers and limitations to successfully completing the prescribed exercise program

\begin{tabular}{lc}
\hline \multicolumn{1}{c}{ Barriers } & $\%$ \\
\hline I did not have any limitations and I participated without any problem & 38.64 \\
I need more time to dedicate to physical activity & 29.55 \\
The internet connection is poor & 22.73 \\
Physical aches or pains & 15.91 \\
My physical condition is poor and I find difficult to improve it & 13.64 \\
I don't have enough materials or a suitable space to perform the exercises & 11.36 \\
I lack motivation to perform physical activity & 9.09 \\
I have never exercised and I am very inexperienced & 4.55 \\
I need the accompaniment of a professional to comply with the program & 4.55 \\
\hline
\end{tabular}

The association between these variables was not significant $\left(X^{2}=0.249 ; p=0.618\right)$; students who failed to achieve at least 150/week of PA and those who complied with the international recommendations of at least $150 \mathrm{~min} /$ week of PA showed a similar frequency of negative emotions. Also, a chi-square test of independence was performed on positive emotions. The relation between these variables was significant $\left(X^{2}=6.415 ; p=0.017\right)$; students who failed to achieve at least $150 \mathrm{~min} /$ week of PA reduced the frequency of positive emotions compared to those who complied with the international recommendations of at least $150 \mathrm{~min} /$ week of PA (Figure 2).

The limitations to completing successfully the prescribed exercise PA program reported by the participants are summarized in table 4.

\section{Discussion}

The purpose of the study was to determine the adherence of college students to a virtual PA program, as well as to record their PA-related experiences during social distancing within the context of the COVID-19 pandemic. The main findings were that students not only increased their PA level, but also their sitting time in almost 2-h over the 10 weeks of intervention. In addition, the students who failed to achieve at least $150 \mathrm{~min} /$ week of PA significantly reduced their positive feelings compared to those who complied with the recommendation, who managed to maintain similar positive feelings after 10 weeks. The lack of time was mentioned as the main barrier to complete the virtual PA program.
The contention measures adopted by Costa Rican government to reduce social contact during the pandemic focused on the regulation of different public and private services, including education, which focused on $100 \%$ virtuality. Other measures were implemented, such as public transportation reduction, temporary closure of non-essential commerce (e.g., parks, fitness facilities, restaurants), and promoting social distancing in general. Overall, these measures might have caused an increase in the time invested in sedentary activities in the population, as it has been reported in other countries [24].

In the present study, on average, the sitting time increased by almost 2-h after 10-weeks of intervention. Yet, the weekly report of PA confirmed that there were no changes in the time spent seated during the intervention and that these results were consistent with the IPAQ data. Thus, the participants before the intervention showed a highly sedentary behavior $(\sim 8.8 \mathrm{~h})$, and this behavior remained unchanged after 10-weeks of the virtual PA program; although, the volume of PA prescribed met the recommendations by the American College of Sports and Medicine during COVID-19 [34, 35]. Furthermore, before the intervention, the sitting time ( $3.8 \mathrm{~h} /$ day) was similar to what was reported in an upper-middle income country ( $3.9 \mathrm{~h} /$ day) and by the end of the program was higher compared to high-income countries ( $4.7 \mathrm{~h} /$ day) [36].

There is compelling evidence indicating that regardless of $\mathrm{PA}$, total sitting time is associated with an increased risk of cardiovascular disease, type 2 diabetes, and obesity $[23,37-40]$. Also, recent cross- 
sectional evidence on the effects of social distancing and confinement measures during the COVID-19 pandemic shows dramatic increases in food consumption [41], decreases in PA [24], and increased psychological disorders such as anxiety, depression, and stress [42]. These conditions are established as disease risk factors likely to increase cardiovascular and cognitive impairment, which will decrease the quality of life of the population.

The prescribed PA program elicited a significant increase in the overall PA (Table 3). According to the categorical assessment of the IPAQ, this result indicates that the participants moved from a low to a moderate level of PA; yet, not enough for everyone to achieve the recommended $150 \mathrm{~min} /$ week of PA and to increase the weekly energy expenditure. However, this finding represents a relevant improvement in terms of the ability to carry out scheduled physical activities during a period of social distancing, given that participants do not have access to fitness centers and other facilities that would stimulate the regular practice of physical activities or sports. These improvements in PA can be counted as preventive strategies against cardiorespiratory impairment and have the potential to improve immune and musculoskeletal function and prevent depression, among other deleterious factors associated with COVID-19 [28, 35, 43, 44].

In this study, the negative feelings did not change between the students who did not achieve at least $150 \mathrm{~min} /$ week of PA and those who did. However, non-complaint students significantly reduced their positive feelings compared to those who achieved the recommendation. The students who met the PA recommendation maintained similar positive feelings after 10-weeks of social distancing, which could be interpreted as a positive finding given that positive feelings did not decrease. The psychological interpretation and potential mechanisms explaining this finding lie beyond the scope of this study, and perhaps factors related to emotions management, personality, self-regulation, self-efficacy, motivation, and student's state and trait characteristics might be needed to explain this finding. Nevertheless, these results suggest a greater resilience of those who performed larger amounts of physical exercise than those who had difficulty complying with the time of PA prescribed in the intervention. Our findings agree with the positive association reported between exercise and the prevention of psychological disorders such as stress or anxiety [45-47] because chronic PA elicits good feelings across time [48].

The novelty of this study was to offering an overview in the context of the application of a virtual PA program for college students in the midst of a pandemic situation, and how to adapt and understand physical programming for this population. As such, this exploratory study aimed at quantifying the effects that the COVID-19 pandemic had on a sample of university students concerning physical activity behavior and feelings at a time when social and educational dynamics underwent profound mandatory changes.

There are methodological limitations that prevent determining more precise effects on general health status. For instance, all data were obtained by self-report measures, and there is evidence suggesting that this data collection strategy may underestimate PA scores and sedentary behavior in college students [49, 50]. However, previous studies have shown that selfreported PA is a valid strategy to record people's behavior under specific circumstances (e.g., social distancing), it is practical, has a low cost, and it is easy to apply [51, 52]. Indeed, since there is no "gold standard" to objectively measure PA and sedentary behavior, and each measure has their own limitations, the use of self-report for these variables remains as an applicable method to determine free-living PA and sedentary behavior and the recommendation is to be cautious when applying these methods $[53,54]$.

We also found deeply rooted sedentary habits similar to those reported previously in adolescents [55], as well as a prevalence of negative feelings and important limitations for implementing PA programs at home, such as a poor internet connection, not having adequate spaces and materials for the practice of PA, or lack of motivation, among others (Table 4). This first glance offers an overview of the context of virtual PA during the pandemic, which offers inputs to better adapt physical programming to university students.

\section{Conclusion}

The sedentary behavior in Costa Rican college students did not change after 10-weeks of a PA virtual program. An increase in PA levels was observed, yet, insufficient to comply with international recommendations, which is a major concern, implying that college activities and daily live conditions from social distancing, caused by COVID-19 virus, refrained students from decreasing sedentary behavior and this might carry out subsequent implications on their quality of life and health. On the other hand, 
participants who complied with PA recommendations were resilient against the social distancing caused by the COVID-19 pandemic. Keeping high physical activity levels in college students should counteract the deleterious effect of forced isolation on students life.

\section{References}

[1] P.T. Katzmarzyk, K.E Powell, J.M. Jakicic, R.P. Troiano, K. Piercy, B. Tennant, 2018 PHYSICAL ACTIVITY GUIDELINES ADVISORY COMMITTEE, Sedentary Behavior and Health: Update from the 2018 Physical Activity Guidelines Advisory Committee, Medicine and Science in Sports and Exercise, 51(6) (2019) 1227-1241. [DOI] [PubMed]

[2] K.L. Piercy, R.P. Troiano, R.M. Ballard, S.A. Carlson, J.E. Fulton, D.A. Galuska, S.M. George, R.D. Olson, The Physical Activity Guidelines for Americans, JAMA, 320(19) (2018) 2020-2028. [DOI] [PubMed]

[3] Rianne M. Weggemans, Frank J. G. Backx, Lars Borghouts, Mai Chinapaw, Maria T. E. Hopman, Annemarie Koster, Stef Kremers, Luc J. C. van Loon, Anne May, Arend Mosterd, Hidde P. van der Ploeg, Tim Takken, Marjolein Visser, G. C. (Wanda) Wendel-Vos, Eco J. C. de Geus \& Committee Dutch Physical Activity Guidelines 2017, The 2017 Dutch Physical Activity Guidelines, International Journal of Behavioral Nutrition and Physical Activity, 15(1) (2018) 58. [DOI]

[4] World Health Organization. Global recommendations on physical activity for health. 2010 [cited 2020 July 18th]; Available from: https://apps.who.int/iris/handle/10665/44399

[5] Carmen Fiuza-Luces, Nuria Garatachea, Nathan A Berger, Alejandro Lucia, Exercise is the Real Polypill, Physiology, 28(5) (2013) 330-358. [DOI] [PubMed]

[6] A. Rathore, and B. Lom, The effects of chronic and acute physical activity on working memory performance in healthy participants: a systematic review with meta-analysis of randomized controlled trials, Systamatic Reviews, 6(1) (2017) 124. [DOI] [PubMed]

[7] Celia Álvarez-Bueno, Caterina Pesce, Iván Cavero-Redondo, Mairena Sánchez-López, Miriam Garrido-Miguel, Vicente MartínezVizcaíno, Academic Achievement and Physical Activity: A Meta-analysis, Pediatrics, 140(6) (2017) e20171498. [DOI] [PubMed]
[8] Amanda Watson, Anna Timperio, Helen Brown, Keren Best, Kylie D Hesketh, Effect of classroombased physical activity interventions on academic and physical activity outcomes: a systematic review and meta-analysis, International Journal of Behavioral Nutrition and Physical Activity, 2017. 14(1) (2017) 114. [DOI] [PubMed]

[9] Sebastian Ludyga, Markus Gerber, Serge Brand, Edith Holsboer-Trachsler, Uwe Pühse, Acute effects of moderate aerobic exercise on specific aspects of executive function in different age and fitness groups: A meta-analysis, Psychophysiology, 53(11) (2016) 1611-1626. [DOI] [PubMed]

[10] Kirk I Erickson, Charles Hillman, Chelsea M Stillman, Rachel M Ballard, Bonny Bloodgood, David E Conroy, Richard Macko, David X Marquez, Steven J Petruzzello, Kenneth E Powell, FOR 2018 PHYSICAL ACTIVITY GUIDELINES ADVISORY COMMITTEE, Physical activity, cognition, and brain outcomes: a review of the 2018 physical activity guidelines, Medicine \& Science in Sports \& Exercise, 51(6) (2019) 12421251. [DOI] [PubMed]

[11] J.M. Briceño-Torres, and J. Moncada-Jiménez, The Effects of Acute Exercise on Arterial Endothelial Diameter: A Meta-Analysis, American Journal of Medicine and Medical Sciences, 8(10) (2018) 251-258. [DOI]

[12] Elizabeth Carpio-Rivera, José Moncada-Jiménez, Walter Salazar-Rojas, Andrea Solera-Herrera, Acute effects of exercise on blood pressure: A meta-analytic investigation, Arquivos Brasileiros de Cardiologia, 106(5) (2016) 422-433. [DOI] [PubMed]

[13] Magno F. Formiga, Rebekah Fay, Savannah Hutchinson, Nicholas Locandro, Angel Ceballos, Alexandra Lesh, Joel Buscheck, Jacy Meanor, Johnny G. Owens and Lawrence P. Cahalin, Effect of aerobic exercise training with and without blood flow restriction on aerobic capacity in healthy young adults: a systematic review with meta-analysis, International Journal of Sports Physical Theraphy, 15(2) (2020) 175-187. [PubMed]

[14] Regis C Pearson, Alyssa A Olenick, Edward S Green, Nathan T Jenkins, Acute exercise effects on postprandial fat oxidation: Meta-analysis and systematic review, Applied Physiology, Nutrition, and Metabolism, 45(10) (2020) 1081-1091. [DOI] [PubMed] 
[15] William E Kraus, Kenneth E Powell, William L Haskell, Kathleen F Janz, Wayne W Campbell, John M Jakicic, Richard P Troiano, Kyle Sprow, Andrea Torres, Katrina L Piercy, 2018 PHYSICAL ACTIVITY GUIDELINES ADVISORY COMMITTEE, Physical Activity, All-Cause and Cardiovascular Mortality, and Cardiovascular Disease, Medicine \& Science in Sports \& Exercise, 51(6) (2019) 1270-1281. [DOI] [PubMed]

[16] Pareja-Galeano, H., N. Garatachea, and A. Lucia, Chapter Twenty-One - Exercise as a Polypill for Chronic Diseases, in Progress in Molecular Biology and Translational Science, C. Bouchard, Editor. 2015, Academic Press. p. 497-526.

[17] Mynor Rodriguez-Hernandez, Jeffrey S Martin, David D Pascoe, Michael D Roberts, Danielle W Wadsworth, Multiple Short Bouts of Walking Activity Attenuate Glucose Response in Obese Women, Journal of Physical Activity and Health, 15(4) (2018) 279-286. [DOI] [PubMed]

[18] M. Rodriguez-Hernandez, and D.W. Wadsworth, The effect of 2 walking programs on aerobic fitness, body composition, and physical activity in sedentary office employees, PLoS One, 14(1) (2019) e0210447. [DOI] [PubMed]

[19] Filipe Rodrigues, Diogo S Teixeira, Henrique $P$ Neiva, Luís Cid, Diogo Monteiro, Understanding Exercise Adherence: The Predictability of Past Experience and Motivational Determinants, Brain Sciences, 10(2) (2020) 98. [DOI] [PubMed]

[20] Christina Gjestvang, Frank Abrahamsen, Trine Stensrud, Lene A. H. Haakstad, Motives and barriers to initiation and sustained exercise adherence in a fitness club setting-A one-year follow-up study, Scandinavian Journal of Medicine \& Science in Sports, 2020. [DOI]

[21] World Health Organization. Coronavirus disease (COVID-19) advice for the public. 2020 [cited 2020 July 18th]; Available from: https://www.who.int/emergencies/diseases/nove I-coronavirus-2019/advice-for-public

[22] World Health Organization, WHO Health Emergency Dashboard. WHO (COVID-19). Costa Rica. 2020; Available from: https://covid19.who.int/region/amro/country/cr

[23] Tiago Peçanha, Karla Fabiana Goessler, Hamilton Roschel, Bruno Gualano, Social isolation during the COVID-19 pandemic can increase physical inactivity and the global burden of cardiovascular disease, American Journal of Physiology-Heart and Circulatory Physiology, 318(6) (2020) H1441-h1446. [DOI] [PubMed]
[24] Geoffrey H Tison, Robert Avram, Peter Kuhar, Sean Abreau, Greg M Marcus, Mark J Pletcher, Jeffrey E Olgin, Worldwide Effect of COVID-19 on Physical Activity: A Descriptive Study, Annals of Internal Medicine, 173(9) (2020) 767-770. [DOI] [PubMed]

[25] A. Crisafulli, and P. Pagliaro, Physical activity/inactivity and COVID-19, European Journal of Preventive Cardiology, (2020). [DOI]

[26] María Martinez-Ferran, Fernando de la GuíaGalipienso, Fabián Sanchis-Gomar, Helios ParejaGaleano, Metabolic Impacts of Confinement during the COVID-19 Pandemic Due to Modified Diet and Physical Activity Habits, Nutrients, 12(6) (2020) 1549. [DOI] [PubMed]

[27] S.J. Carter, M.N. Baranauskas, and A.D. Fly, Considerations for Obesity, Vitamin $D$, and Physical Activity Amid the COVID-19 Pandemic, Obesity (Silver Spring), 28(7) (2020) 1176-1177. [DOI] [PubMed]

[28] Peijie Chen, Lijuan Mao, George P. Nassis, Peter Harmer, Barbara E. Ainsworth and Fuzhong Li, Coronavirus disease (COVID-19): The need to maintain regular physical activity while taking precautions, Journal of Sport and Health Science, 9(2) (2020) 103-104. [DOI] [PubMed]

[29] Peijie Chen, Lijuan Mao, George P. Nassis, Peter Harmer, Barbara E. Ainsworth and Fuzhong Li, Returning Chinese school-aged children and adolescents to physical activity in the wake of COVID-19: Actions and precautions, Journal of Sport and Health Science, 9(4) (2020) 322-324. [DOI] [PubMed]

[30] Stommel, M. and C.A. Schoenborn, Accuracy and usefulness of BMI measures based on selfreported weight and height: findings from the NHANES \& NHIS 2001-2006, BMC Public Health, 9(1) (2009) 421. [DOI] [PubMed]

[31] Cora L Craig, Alison L Marshall, Michael Sjöström, Adrian E Bauman, Michael L Booth, Barbara E Ainsworth, Michael Pratt, Ulf Ekelund, Agneta Yngve, James F Sallis, Pekka Oja, International physical activity questionnaire: 12-country reliability and validity, Medicine \& Science in Sports \& Exercise, 35(8) (2003) 1381-95. [DOI] [PubMed]

[32] B.E. Ainsworth, W.L. Haskell, A.S. Leon, D.R. Jacobs Jr, H.J. Montoye, J.F. Sallis, R.S. Paffenbarger Jr, Compendium of physical activities: classification of energy costs of human physical activities, Medicine \& Science in Sports \& Exercise, 25(1) (1993) 71-80. [DOI] [PubMed] 
[33] Márcio de Almeida Mendes, Inácio da Silva, Virgílio Ramires, Felipe Reichert, Rafaela Martins, Rodrigo Ferreira, Elaine Tomasi, Metabolic equivalent of task (METs) thresholds as an indicator of physical activity intensity, PLoS One, 13(7) (2018) e0200701. [DOI] [PubMed]

[34] Keri L Denay, Rebecca G Breslow, Meredith N Turner, David C Nieman, William O Roberts, Thomas M Best, ACSM Call to Action Statement: COVID-19 Considerations for Sports and Physical Activity, Current Sports Medicine Reports, 19(8) (2020) 326-328. [DOI] [PubMed]

[35] G.F., Dunton, B. Do, and S.D. Wang, Early effects of the COVID-19 pandemic on physical activity and sedentary behavior in children living in the U.S, BMC Public Health, 20(1) (2020) 1351. [DOI] [PubMed]

[36] M Mclaughlin, A J Atkin, L Starr, A Hall, L Wolfenden, R Sutherland, J Wiggers, A Ramirez, P Hallal, M Pratt, B M Lynch, K Wijndaele, Sedentary Behaviour Council Global Monitoring Initiative Working Group, Worldwide surveillance of self-reported sitting time: a scoping review, International Journal of Behavioral Nutrition and Physical Activity, 17(1) (2020) 111. [DOI] [PubMed]

[37] Jacob E. Barkley, Andrew Lepp, Ellen Glickman, Greg Farnell, Jake Beiting, Ryan Wiet, and Bryan Dowdell, The Acute Effects of the COVID-19 Pandemic on Physical Activity and Sedentary Behavior in University Students and Employees, International Journal of Exercise Science, 13(5) (2020) 1326-1339. [PubMed]

[38] Josephine Y Chau, Anne C Grunseit, Tien Chey, Emmanuel Stamatakis, Wendy J Brown, Charles E Matthews, Adrian E Bauman, Hidde P van der Ploeg, Daily sitting time and all-cause mortality: a meta-analysis, PLoS One, 2013. 8(11) (2013) e80000. [DOI] [PubMed]

[39] E.S. Ford, and C.J. Caspersen, Sedentary behaviour and cardiovascular disease: a review of prospective studies, International Journal of Epidemiology, 41(5) (2012) 1338-1353. [DOI] [PubMed]

[40] Richard Patterson, Eoin McNamara, Marko Tainio, Thiago Hérick de Sá, Andrea D Smith, Stephen J Sharp, Phil Edwards, James Woodcock, Søren Brage, Katrien Wijndaele, Sedentary behaviour and risk of all-cause, cardiovascular and cancer mortality, and incident type 2 diabetes: a systematic review and dose response meta-analysis, European Journal of
Epidemiology, 33(9) (2018) 811-829. [DOI] [PubMed]

[41] Ammar, A., et al., Effects of COVID-19 Home Confinement on Eating Behaviour and Physical Activity: Results of the ECLB-COVID19 International Online Survey, Nutrients, 12(6) (2020) 1583.. [DOI] [PubMed]

[42] Nader Salari, Amin Hosseinian-Far, Rostam Jalali, Aliakbar Vaisi-Raygani, Shna Rasoulpoor, Masoud Mohammadi, Shabnam Rasoulpoor, Behnam Khaledi-Paveh, Prevalence of stress, anxiety, depression among the general population during the COVID-19 pandemic: a systematic review and meta-analysis, Global Health, 16(1) (2020) 57. [DOI] [PubMed]

[43] Jeffrey A.Woods, Noah T.Hutchinson, Scott K.Powers, William O.Roberts, Mari Carmen Gomez-Cabrera, Zsolt Radak, Istvan Berkes, Anita Boros, Istvan Boldogh, Christiaan Leeuwenburgh, Hélio José Coelho-Júnior, Emanuele Marzetti, Ying Cheng, Jiankang Liu, J. Larry Durstine, Junzhi Sun, Li LiJi, The COVID-19 pandemic and physical activity, Sports Medicine and Health Science, 2(2) (2020) 55-64. [DOI]

[44] Grenita Hall, Deepika R Laddu, Shane A Phillips, Carl J Lavie, Ross Arena, A tale of two pandemics: How will COVID-19 and global trends in physical inactivity and sedentary behavior affect one another?, Progress in Cardiovascular Diseases, 64 (2021) 108-110. [DOI] [PubMed]

[45] E. Aylett, N. Small, and P. Bower, Exercise in the treatment of clinical anxiety in general practice a systematic review and meta-analysis, BMC Health Services Research, 18(1) (2018) 559. [DOI] [PubMed]

[46] Amanda L Rebar, Robert Stanton, David Geard, Camille Short, Mitch J Duncan, Corneel Vandelanotte, A meta-meta-analysis of the effect of physical activity on depression and anxiety in non-clinical adult populations, Health Psychology Review, 9(3) (2015) 366-78. [DOI] [PubMed]

[47] Chong-Wen Wang, Celia H Y Chan, Rainbow T H Ho, Jessie S M Chan, Siu-Man Ng, Cecilia L W Chan, Managing stress and anxiety through qigong exercise in healthy adults: a systematic review and meta-analysis of randomized controlled trials, BMC Complementary and Alternative Medicine, 14 (2014) 8. [DOI] [PubMed]

[48] Amanda L. Hyde, David E. Conroy, Aaron L. Pincus, and Nilam Ram, Unpacking the feel-good effect of free-time physical activity: between- 
and within-person associations with pleasantactivated feeling states, Journal of Sport and Exercise Psychology, 33(6) (2011) 884-902. [PubMed]

[49] Valerie J Silfee, Christina F Haughton, Danielle E Jake-Schoffman, Andrea Lopez-Cepero, Christine N May, Meera Sreedhara, Milagros C Rosal, Stephenie $C$ Lemon, Objective measurement of physical activity outcomes in lifestyle interventions among adults: A systematic review, Preventive Medicine Reports, 11 (2018) 74-80. [DOI] [PubMed]

[50] Oscar Castro, Jason Bennie, Ineke Vergeer, Grégoire Bosselut, Stuart J H Biddle, How Sedentary Are University Students? A Systematic Review and Meta-Analysis, Prevention Science, 21(3) (2020) 332-343. [DOI] [PubMed]

[51] Barbara Ainsworth, Lawrence Cahalin, Matthew Buman, Robert Ross, The Current State of Physical Activity Assessment Tools, Progress in Cardiovascular Diseases, 57(4) (2015) 387-395. [DOI] [PubMed]

[52] C.E. Tudor-Locke, and A.M. Myers, Challenges and Opportunities for Measuring Physical Activity in Sedentary Adults, Sports Medicine, 31(2) (2001) 91-100. [DOI] [PubMed]

[53] R.K. Dishman, R.A. Washburn, and D.A. Schoeller, Measurement of Physical Activity, Quest, 53(3) (2001) 295-309. [DOI]

[54] S.A. Prince, K.B. Adamo, M.E. Hamel, J. Hardt, S.C. Gorber \& Mark Tremblay, A comparison of direct versus self-report measures for assessing physical activity in adults: a systematic review, International Journal of Behavioral Nutrition and Physical Activity, 5(1) (2008) 56. [DOI]

[55] M. Meneses Montero, and F. Ruiz Juan, Longitudinal study on leisure time behaviors and physical and sports activity level in students from Costa Rica, Mexico and Spain, Retos, 31 (2017) 219-226. [DOI]
Funding

No funding was received to carry out this study

Ethics approval

This study was approved by Institutional ethics committee.

\begin{abstract}
Authors Contribution
Keven Santamaria-Guzman - Conceived the study design, methodology, and analysis, collected data, performed data analysis, wrote, edited and approved the manuscript. Mynor Rodriguez-Hernandez - Conceived the study design, methodology, and analysis, collected data, contributed to data analysis, wrote, edited and approved the manuscript. Jose Moncada-Jimenez Contributed to the study design, contributed to the data analysis, edited and approved the paper
\end{abstract}

Does this article screened for similarity? Yes.

Conflict of interest

The authors have no conflicts of interest to declare that they are relevant to the content of this article.

\section{Informed consent}

Written consent was obtained from the participants

About The License

(c) The Author(s) 2021. The text of this article is open access and licensed under a Creative Commons Attribution 4.0 International License 